\title{
POLEMIK EPISTEMOLOGI PANCASILA DAN DEMOKRASI YANG KONSTRUKTIF BESERTA IMPLEMENTASINYA
}

\author{
Oleh: \\ Agustinus Edward Tasma dan Heru Santosa
}

\begin{abstract}
Abstrak
As cristalization values of Indonesion basics, Pancasila has reflections of our self of Nations. Pancasila has representation of everything differents in Nusantara Islands. With Pancasila it can be used on missions for our governents.

In Indonesian conditions has wached essential of Pancasila as phylosophies groundlach and we have concern of phylosophy as way of live by differents in Indonesian governent.
\end{abstract}

\section{Pendahuluan}

Telah 59 tahun sejarah perjalanan kita sebagai sebuah negara bangsa. Sepanjang rentang waktu itu pula, perdebatan mengenai dasar dan tujuan kita berbangsa dan bernegara masih marak dan gandrung diperbincangkan publik. Pasalnya, konstruksi kita sebagai sebuah negara bangsa dibangun di atas mozaik-mozaik perbedaan baik suku, agama, ras (SARA), bahasa dan budaya dan heteroge-nitas tersebut selalu dual dan dilematis.

Sebelum angin reformasi berhembus di persada nusantara, heterogenitas tersebut dalam pengalaman dan perjalanan bersama ( $\mathrm{co}$ exist) kita sebagai sebuah negara bangsa, sepintas tidak menjadi dan bahkan tidak pernah menjadi sebuah persoalan. Artinya, perbedaanperbedaan tersebut tidak membuat kita lantas merasa menjadi "berbeda" satu dan lainnya sebagai anggota sebuah keluarga besar bernama negara bangsa Indonesia. Seakan sepakat dengan Sumpah Pemuda, kita selalu merasa sebagai satu bangsa, satu bahasa dan satu tanah air, yaitu Indonesia.

Pasca bergulirnya reformasi, konstruksi negara bangsa yang dibangun di atas perbedaan tersebut muncul dalam wajahnya yang lain. Setelah sekian lama - terutama pada masa Oder Baru tenggelam di bawah permukaan, perbedaan yang semula dianggap sebagai "sumbu perekat" integrasi negara bangsa bernama Indo-nesia ini justru menjadi peletup disintegrasi. Pikiran kita seakan-akan terbuka ketika heterogenitas tersebut menimbulkan konflik horisontal 
antar kita sebagai sesama warga bangsa. Aceh, Papua, dan Kepulauan Riau menuntut untuk berpisah dengan Negara Kesatuan Republik Indonesia (NKRI), Ambon, Poso, Kupang, Sampit, Ketapang dan beberapa daerah lainnya bergolak penuh darah dalam konflik berlatar SARA.

Puncak semua tuntutan itu terjadi ketika Pancasila sebagai filsafat negara digugat eksistensinya. Pancasila, menurut kalangan yang menggugatnya itu, di-anggap tidak relevan lagi dengan kondisi zaman dan bahkan dipandang sebagai akar dari krisis multidimensi yang kita alami, termasuk persoalan-persoalan di atas.

Pertanyaan yang muncul di sini adalah; benarkah Pancasila tidak lagi relevan dan menjadi akar persoalan yang membenamkan kita dalam kubangan lumpur krisis di segala lini kehidupan, seperti yang diklaim oleh kalangan yang menggugat eksistensi Pancasila tersebut? Persis pertanyaan-pertanyaan itu yang ingin disingkapi sekaligus disikapi oleh makalah ini.

\section{Kerangka Teori}

Secara umum, bangunan makalah ini mengacu pada pengertian Pancasila sebagai sistem filsafat. Dalam Pancasila Secara Ilmiah Populer, Notonegoro membagi pengertian filsafat Pancasila dalam dua arti yaitu berdasarkan objek forma dan objek materinya. Sebagai objek forma, Pancasila adalah pembahasan secara filsafati, yaitu pembahasan sampai pada hakikatnya yang terdalam. Sebagai objek materi, filsafat Pancasila adalah suatu sistem pemikiran yang rasional, sistematis, terdalam dan menyeluruh tentang Pancasila Polemik Epistemologi dapat kita batasi sebagai persoalan-persoalan sekitar seputar eksistensi Pancasila yang berkaitan dengan cara, metode, strategi dan norma, agar sesuatu yang lain dapat kembali ke sebabnya. Sedangkan demokrasi yang dimaksud di sini lebih merujuk aspek aksiogis Pancasila sebagai sebuah sistem filsafat yang universal dan komprehensif atau utuh berdasarkan tujuan yang tertera dalam Pancasila (Heru Santoso at all, 2002).

Maka objek kajiannya lebih terpusat pada implementasi Pancasila dalam kehidupan berbangsa dan bernegara terutama dalam negara Orde Baru yang dalam hal ini terkait erat dengan praktek demokrasi di era tersebut. Sedangkan Negara Orde Baru yang dimaksudkan di sini adalah, Negara Kesatuan Republik Indonesia di bawah kekuasaan regim Soeharto (Heru Santoso at all, 2002). 


\section{Pembahasan}

Historiografi Indonesia selama 59 tahun berdirinya, terutama sebagai sebuah negara bangsa dalam pengertian modern, adalah sebuah kisah sejarah panjang dan penuh liku. Iwan Gardono dalam sebuah tulisannya (Kompas, 22 Desember 1999) mengingatkan kembali kepada anak bangsa konsensus awal yang kemudian menjadi embrio awal terbentuknya NKRI, yaitu Sumpah Pemuda 29 Oktober 1928 dan Proklamasi RI 17 Agustus 1945. Dengan membandingkan sejarah eksistensi bangsa-bangsa lain di dunia, seperti Amerika, Inggris, dan Norwegia yang sepi dari gejolak internal pasca 100 tahun bereksistensi, Iwan menekankan bahwa usia 50 tahun bagi sebuah negara bangsa yang dibangun di atas heterogenitas etnis, suku, agama, budaya dan bahasa seperti Indonesia merupakah sebuah titik kritis eksistensi, di mana perbedaan yang ada harus dimanage dengan baik agar tidak terjadi gejolak yang bersumber dari heterogenitas tersebut.

Namun kemunculan fajar reformasi di zamrud katulistiwa pada Mei 1998 yang ditandai runtuhnya kekuasaan otoritarian Orde Baru, ternyata menjadi babak baru bagi ko-eksistensi tersebut dan seakan menjadi sintesa mimpi buruk Iwan Gardono di atas. Pikiran kita seolah-olah mulai terbuka ketika menyaksikan perbedaan-perbedaan tersebut menimbulkan konflik terbuka antar kita sebagai sesama warga bangsa.

Konflik horisontal bernuansa SARA yang menghantam Ambon, Ketapang, Kupang, dan Poso, lalu gejala disintegrasi-separatis yang muncul dalam rupa tuntutan beberapa daerah (Aceh, Papua, Riau) untuk berpisah dari Negara Kesatuan Republik Indonesia (NKRI) hingga tuntutan sebagian kalangan yang ingin agar Pancasila tidak lagi menjadi asas tunggal, adalah bukti tak terbantahkan betapa perbedaan-perbedaan tersebut ternyata gagal kita sinergikan untuk membangun fondasi yang kuat bagi sebuah rumah bernama Indonesia.

Berikut, makalah ini mencoba melacak masalah-masalah seputar implementasi Pancasila dalam negara Orde Baru yang hemat kami menjadi embrio munculnya tuntutan itu.

\section{Implementasi Pancasila dan Polemik Epistemologi}

Sejak resmi berdiri sebagai sebuah negara bangsa dalam pengertian modern, eksistensi Pancasila sebagai landasan idiil NKRI selalu diwarnai polemik. Episentrum polemik terutama pada interpretasi Pancasila sebagai ideologi negara (state-ideology) khususnya dimensi kesejarahan dan fungsinya. 
Kelahiran Pancasila misalnya. Hingga tahun 1965 hanya ada tafsir tunggal dan tidak ada perdebatan mengenai dimensi sejarah kelahirannya. Bung Karno memainkan peran tunggal atas keduanya, tafsir sekaligus sejarah. Tetapi mainsteam sejarah selalu ditentukan oleh pihak yang keluar sebagai pemenang dalam sebuah pergulatan politik. Dengan runtuhnya kekuasaan Soekarno dan munculnya Soeharto sebagai seorang figur baru, maka hitoriografi Indonesia pasca 1965 didominasi oleh militer dan kemudian oleh birokrasi. Bila pada masa Bung Karno Pancasila berkontestasi ideologi-ideologi lain seperti Nasional, Agama, dan Komunis (NASAKOM), pada masa yang dibabtis dengan nama Orde Baru ini, Pancasila ditetapkan sebagai ideologi Tunggal (mono-ideology). Isi Pancasila yang pernah diperas menjadi tiga sila dan empat sila pada era Orde Lama "dikembalikan" ke lima sila, sementara "penggalinya" dikaburkan, menjadi bukan hanya bung Karno. Dengan demikian, ruang tafsir atas Pancasila menjadi otoritas regim dan tafsiran-tafsiran di luar itu dianggap sebagai sebuah kesalahan berpikir (falacy) yang berakibat pada ancaman subversif dari negara. Implementasi ketentuan ini dapat kita lihat dari proses Fusi partai-partai Politik yang memaksakan Pancasila sebagai mono-ideology (Hermawan Sulistyo, 2004). Dalam kondisi seperti ini, ideologi rentan menjadi alat instrumentasi sebuah regim untuk kepentingan kekuasaannya, ketimbang sebagai sebuah cara pandang bersama yang dapat mengayomi semua golongan dan kepentingan yang ada.

Kedua, persoalan rumusan Pancasila sebagai sebuah pandangan hidup bangsa. Seperti yang dilansir Achadiat M. dalam Polemik Kebudayaan (Achadiat K. Miharja, 1984), pernyataan antara Pancasila sebagai Pandangan Hidup Bangsa Indonesia selama beratus-ratus tahun dan sekaligus merupakan sebuah falsafat politik adalah sesuatu yang kontradiktif (contradictio in terminis). Sebagai pandangan hidup yang digali dan berurat akar dalam kebudayaan Indonesia yang heterogen, Pancasila belum merupakan dan memang tidak dapat berupa rumusan. Sebagai sebuah rumusan Pancasila adalah "produk historis" dari sebuah momentum tertentu, tepatnya ketika Supomo, M. Yamin, dan Soekarno merumuskan butir-butir pemikirannya dalam sidang pertama Dokuritsu Zyunbi Tyoosakai mengenai dasar yang akan kita pergunakan dalam membangun sebuah negara bangsa bernama Indonesia.

Ketiga, polemik apakah Sriwijaya, Majapahit dan beberapa kerajaan yang pernah mencoba menyatukan Nusantara di Indonesia sebagai sebuah kontinum sejarah yang linear dengan Indonesia pasca 
proklamasi, dengan sedikit retoris, Daniel Dakhidae dalam pengantar buku Imagined Communities karya Benedict Anderson (2001) mempertanyakan hal ini dengan sangat tajam. Sedikitnya ada dua alasan yang dia kemukakan. Pertama, otensitas nama negara kita, Indonesia. Menurutnya nama ini adalah pemberian orang asing, tepatnya para penjajah dan ilmuwan-ilmuwan antrop yang mengambilnya dari bahasa Yunani. Jika kerajaan-kerajaan tersebut merupakan kontinum yang linier dengan NKRI mengapa nama negara kita bukan Republik Nusantara, seperti tujuan ekspansi teritorial seperti ekspedisi pemalayu yang dijalankan oleh kerajaan-kerajaan ini? Mengapa nama pem-berian orang asing tadi mampu mengatasi nama Nusantara yang merupakan nama dari kosa kata asli budaya kita? Kedua, ekspedisi teritori tersebut bukan bertujuan untuk membangun sebuah negara bangsa yang sama seperti cara pandang kita terhadap "Wawasan Nusantara" selama ini, melainkan demi keagungan dan kema-syuran kerajaan dan raja-rajanya. Artinya, orientasi ekspansi teritorial kerajaan-kera-jaan tersebut bukan untuk mendirikan sebuah "kerajaan besar" bernama Indonesia (Benedict Anderson, 2001).

\section{Pancasila sebagai State-ideologi dan Kepentingan Kekuasaan}

Sejak semula kekuasaan selalu berwajah ganda, sekaligus mempesona dan menakutkan. Mempesona karena manusia pada dirinya memiliki naluri untuk bertahan hidup (survival) dan untuk itu memerlukan sebuah otoritas atau power yang bisa dijadikan pegangan dalam bertindak, dan bertingkah laku. Pada sisi lain, sekaligus menakutkan karena dapat disalahgunakan untuk menindas makhluk hidup lainnya (homo humini lupus) sehingga tidaklah berlebihan dengan nada yang sitir Lord Action, seorang ilmuwan politik asal Inggris menyatakan bahwa kekuasaan itu cenderung korup (power absolute tends to corrupt absolutely).

Antara ideologi negara dan kekuasaan tentu memiliki relevansi yang sangat erat. Penguasa membutuhkan ideologi sebagai basis legitimasi atas kekuasaan yang dimilikinya, sedangkan ideologi adalah pandangan hidup sebuah bangsa yang menyangkut nilai-nilai dasar bernegara, terlepas dari apakah ideologi tersebut bersifat terbuka atau tertutup (Magnis Suseno, 2003).

Dalam lembaran sejarah bangsa kita, terutama dalam Orde Baru, terlihat jelas benang merah antara kekuasaan dan ideologi. Yang menjadi persoalan adalah ideologi yang secara normatif menundukkan 
setiap warga negara dan bahkan negara itu sendiri di bawahnya, malah menjadi alat kepentingan negara untuk menindas warga negara (Magnis Suseno, 2003). Artinya, fungsi ideologi sebagai payung bersama yang mengatasi seluruh perbedaan dalam masyarakat telah terkooptasi menjadi alat negara untuk kepentingannya. Maka ketika kepentingan penguasa vis a vis dengan kepentingan masyarakat, masyarakat selalu menjadi tumbal atas nama ideologi tersebut. Sebut saja kasus-kasus pembredelan pers yang pernah dilakukan penguasa Orde Lama dan Orde Baru untuk mematikan kontrol sosial masyarakat terhadap kinerjanya atau keluh kesah masyarakat kecil (wong cilik) yang selalu menjadi tumbal dalam sebuah proyek penguasa seperti pembuatan lapangan Golf, pusat perbelanjaan dan hiburan, dan lain-lain.

\section{Pancasila sebagai Ideologi Terbuka vs Ideologi Tertutup}

Sejatinya, Pancasila adalah sebuah ideologi yang bersifat terbuka. Ada beberapa alasan yang bisa diangkat untuk menjelaskan hal ini. Pertama, Pancasila tidak bersifat kaku atau tertutup melainkan terbuka, aktual, dinamis-reformatif, responsif dan mengikuti zaman. Kedua, Pancasila tidak bersifat utopis atau hanya berisi ide-ide yang mengawang tanpa penjabaran konkrit operasional dalam kehidupan bangsa (Heru Susanto at all., 2002). Ketiga, Pancasila merupakan kristalisasi nilai-nilai luhur bangsa. Dengan demikian Pancasila adalah jati diri bangsa dan tidak menafikkan ele-men budaya-budaya lain yang ada, malah akan di-inkulturasikan dengan nilai-nilai yang telah ada dalam Pancasila. Jadi, Pancasila "welcome" terhadap budaya lain, sepanjang budaya tersebut sesuai dan dapat memperkaya khazanah budaya bangsa.

Meskipun demikian dalam negara Orde Baru, Pancasila justru menunjukkan wajah yang tertutup. Pancasila yang sejatinya bersifat terbuka muncul sebagai ideologi tertutup dengan hanya menjadi instrumentasi regim penguasa untuk melanggengkan kekuasaan, tidak terbuka terhadap pandangan lain seperti interpretasi alternatif terhadap Pancasila - tafsiran Pancasila hanya menjadi monopoli otoritas atau penguasa, serta kooptasi Pancasila oleh negara yang berujung pada melemahnya posisi tawar warga negara di hadapan penguasa. Akibat instrumentasi, kooptasi dan sakralisasi Pancasila sebagai asas tunggal (mono-ideology) tersebut, Orde Baru akhirnya menjadi sebuah sejarah kelam tentang tidak-berimbangnya peran negara vis a vis warga negara, di mana hak-hak warga negara dikangkangi oleh regim atas 
nama ideologi (hak berpendapat dan kontrol dengan membungkam pers, hak berserikat dan berpolitik dengan mengeliminir serta melebur parpol), dan penumpukan kekuasaan pada satu lembaga (Presiden) yang kemudian bermuara pada kekuasaan yang tiran-otoriter.

\section{Implementasi Demokrasi di Indonesia}

Munculnya reformasi di zamrud khatulistiwa yang ditandai oleh jatuhnya kekuasaan despotik-otoritarian Orde Baru pada 21 Mei 1998, telah membawa impli-kasi pada seluruh dimensi kehidupan berbangsa dan bernegara. Sebut saja sistem politik, hukum dan pemerintahan sebagai contoh. Selama reformasi bergulir terjadi perubahan yang sangat signifikan pada sistem dan lembaga-lembaga tersebut. Fungsi dan kedudukannya yang mandul dan tumpang tindih pada era-era sebelumnya, menjadi lebih maksimal dan jelas pada era reformasi.

Jika melihat agenda awal reformasi, perubahan-perubahan itu tentu saja adalah konsekuensi logis dari reformasi yang menginginkan perubahan secara menyeluruh pada segala aspek kehidupan (total reform). Maka pembenahan dan pengembalian fungsi lembagalembaga tersebut secara normatif menjadi sesuatu tuntutan sejarah yang sine quo non (urgen).

Berbicara tentang implementasi demokrasi di Indonesia, kita bicara tentang sebuah proses pasang surut yang panjang. Pasalnya demokrasi mengutip Robert Dahl, bukanlah sesuatu yang hidup dalam ruang vakum, di mana dalam sebuah negara varian-varian demokrasi dapat diterapkan sekaligus (Robert A. Dahl, 1999). Seperti yang dikatakan Dahl, negara kita tercatat pernah menerapkan beberapa varian demokrasi, seperti demokrasi Liberal, terpimpin dan demokrasi Pancasila (Miriam Budiardjo, 2000). Dalam negara Orde Baru, implementasi demokrasi sangat terpusat dalam lembaga eksekutif atau dalam hal ini presiden yang memang diberi mandat oleh konstitusi sebagai menjadi pemimpin pemerintahan dan negara sekaligus (presiden-sial system).

Betul bahwa secara formal Orde Baru mengklaim sebagai regim yang demokratis di mana instrumen demokrasi seperti parpol, pers, pembagian kekuasaan antar lembaga seperti eksekutif, yudikatif, dan legislatif berjalan seimbang, namun dalam prakteknya kekuasaan tetap menumpuk pada satu tangan, yaitu lembaga eksekutif.

Jika merujuk pada konsep asli kekuasaan, seperti yang dicetuskan oleh Emanuel Kant, dan John Locke tentang mekanisme pembagian kekuasaan antar organ-organ negara (trias Politika) 
(Miriam Budiardjo, 2000), maka praktek demokrasi dalam konteks ini di masa negara Orde Baru adalah sebuah patologi yang mencerminkan otoritarian kekuasaan dalam tangan eksekutif (eksekutif heavy). Akibatnya kekuasaan menjadi absolut, tidak ada mekanisme check and balance, mandulnya peran dan fungsi legislatif dan yudikatif serta partisipasi masyarakat dalam mekanisme pembuatan keputusan (Decision Making) yang pada gilirannya bermuara pada ketiadaan kontrol baik sosial maupun politik atas legitimasi regim serta Pemilu yang curang dan syarat manipulasi. Persis di titik ini, Pancasila sebagai ideologi negara lagi-lagi diseleweng-kan. Vox Populi vox Dei - suara rakyat adalah suara Tuhan, seperti yang diamanat-kan sila Kerakyatkan yang dipimpin oleh hikmat kebijaksanaan dalam permusyawa-ratan dan perwakilan yang merupakan entry point pelaksanaan demokrasi di Indonesia, hanya berhenti pada jargon tanpa sebuah realitas implementatif. Dengan sangat bagus, Dakhidae melukiskan ini sebagai kondisi demokrasi yang bukan "daulat rakyat" melainkan "daulat tuanku” (baca: negara) (Daniel Dakhidae, 2002).

\section{Kesimpulan}

Dari berbagai uraian kami menyangkut realitas implementasi Pancasila dalam negara Orde Baru di muka, maka klaim kalangan yang menuntut dan menyalahkan Pancasila sebagai akar persoalan yang kita hadapi saat ini sekaligus irelevan, adalah tuntutan yang sama sekali tidak mendasar.

Sebagai kristalisasi nilai-nilai luhur bangsa dan dasar berIndonesia, Panca-sila adalah cerminan jati diri bangsa, Pancasila adalah representasi "kebinekaan" yang tersebar di seluruh penjuru persada nusantara. Dengan adanya Pancasila, perbedaan-perbedaan yang kita miliki dapat disinergikan, Pancasila mengatasi perbedaanperbedaan tersebut dan menyatukan kita dalam sebuah kebersamaan sebagai sebuah negara bangsa.

Bahwa Pancasila sebagai ideologi negara pernah diselewengkan dan apa yang digariskan dalam konsepsi Pancasila tidak selaras dengan praktek dalam kehidupan berbangsa dan bernegara, yang pada akhirnya menjadi pemicu integrasi, itu lebih dikarenakan aspek human error, yaitu nafsu kekuasaan dan ketamakan manusia untuk survive dengan menindas manusia lainnya (homo humini lupus) dan kesalahan manajerial dalam mengelola perbedaan tersebut dalam hal ini penguasa Orde Baru. 
Jadi, bukan Pancasila yang menjadi permasalahan dan sampai kapan pun tidak akan pernah menjadi masalah. Bahkan akan terus relevan tanpa terbatas ruang dan waktu, karena Pancasila adalah ideologi yang terbuka yang mana mampu mengatasi zaman atau adaptif dan responsif terhadap tuntutan perubahan zaman.

Kondisi seperti itu, hemat kami, pada dirinya harus dimaknai untuk menjer-nihkan kembali pandangan kita tentang hakikat Pancasila sebagai filsafat dasar kita ber-Indonesia, agar kita sadar akan fondasi negara bangsa kita, yaitu kebinekaan. Maka, heterogenitas tersebut harus disikapi secara arif, yaitu dengan menempatkannya kembali sebagai "lem perekat" integrasi kita sebagai sesama warga negara-bangsa yang bernama Indonesia.

\section{Catatan Kritis}

Sejalan dengan reformasi yang menghendaki perubahan, masa reformasi menjadi sebuah turning point bagi implementasi Pancasila dan demokrasi di Indonesia secara benar. Sejauh ini, 'perubahan' yang menjadi cetak biru (blue print) reformasi memang mulai kelihatan. Refleksinya terlihat dalam peran dan fungsi lembaga demokrasi yang "macet" pada era Orde Baru - menjadi semakin jelas dan optimal, struktur pembagian kekuasaan yang jelas antara lembagalembaga demokrasi seperti eksekutif, legilatif, dan yudikatif. Penghargaan atas partisipasi publik dalam mekanisme decision making, penghormatan atas hak-hak dasar warga negara yang tercermin dalam keikutsertaan dalam partai politik (multy party system), mengontrol kinerja pemerintah melalui media masa yang bebas serta partisipasi dalam pemilu yang semakin rasional-objektif (tercatat telah tiga kali kita menyelenggarakan Pemilu yang jujur dan adil seperti amanat demokrasi). Dalam konteks itu, Pemilu yang kita jalankan kali lalu (Pemilu 2004) adalah sebuah bukti tak terbantahkan betapa implementasi demokrasi bukan lagi sebuah utopia atau khayalan semata, di bumi Indonesia. Pasalnya, selain terwujudnya penghargaan atas partisipasi rakyat terutama dengan memilih secara langsung pejabat negara, baik legislatif maupun eksekutif (presiden dan wakil presiden), di lain pihak mimpi besar kita menjadi salah satu negara kampium demokratis yang sejajar dengan negara-negara demokrasi lainnya menjadi sebuah keniscayaan. Namun, semua itu tentu saja belum cukup. Demokrasi bukanlah sebuah obat mujarab yang bisa menyembuhkan krisis multidimensi yang mendera bangsa kita selama ini. Kita harus terus berusaha agar tujuan konsensus yang 
kita buat seperti yang terdapat dalam Pancasila benar-benar menjadi kenyataan.

Karenanya, Pancasila harus diletakkan kembali sesuai dengan fungsinya sebagai state ideology yang mengayomi heterogenitas yang kita miliki bukan hanya kepentingan penguasa dan kekuasaan semata. Dengan begitu heterogenitas RAS, bahasa, dan kebudayan yang kita miliki akan menjadi persoalan, namun lebih mempererat integrasi antara kita, sebagai negara bangsa yang satu bahasa, tanah air, dan bangsa yaitu Indonesia.

\section{Daftar Pustaka}

Anderson, Benedict. 2001. Imagined Comunities; KomunitasKomunitas Terbayang. INSIST Press.

Budiardjo, Miriam. 2000. Dasar-dasar Ilmu Politik. Jakarta: Gramedia.

Dahl, Robert A. 1999. On Democration. Yale University Press.

Dakhidae, Daniel. 2002. Cendekiawan Orde Baru. Jakarta: Gramedia.

Kaelan. 1996. Filsafat Pancasila. Yogyakarta: Paradigma.

Mihardja, Achdiat K. 184. Polemik Kebudayaan. Jakarta: LP3S.

Sulistyo, Hermawan. 2004. Republik Burung Hantu, Jakarta: Kelana Nusantara.

Santoso, Heru, at all. 2002. Sari Pendidikan Pancasila dan UUD 1945 beserta Perubahannya. Yogyakarta: Tiara Wacana.

Suseno, Magnis. 2003. Kuasa dan Moral. Jakarta: Gramedia.

\section{Biodata Penulis}

Agustinus Edward Tasma adalah mahasiswa semester IX FISIP UPN Yogyakarta.

Ir. Heru Santosa, M.Hum. adalah dosen MKU pada Universitas Pembangunan Nasional Yogyakarta, menamatkan S2 Ilmu Filsafat pada tahun 1998 di UGM. 